\title{
O-Y (Oxygen-Yttrium)
}

\section{H. Okamoto}

The Y-O phase diagram in [Massalski2] was drawn based on the assessment of [1990Car]. This system was assessed again by [1996Bou, 1996Gro], as reported by [19980ka]. A similar result was obtained by [1996Lys] also. The composition range of the phase diagrams reported above were all 0 to $\sim 70$ at. $\% \mathrm{O}$. The temperature range was also limited up to $\sim 2600^{\circ} \mathrm{C}$.

The complete Y-O phase diagram was obtained by thermodynamic modeling by [2007Dju], as shown in Fig. 1. No supporting data are available for the expanded range. Nevertheless this phase diagram will serve as a good guideline in determining the phase boundaries experimentally.

\section{References}

1990Car: O.N. Carlson, The O-Y (Oxygen-Yttrium) System, Bull. Alloy Phase Diagr., 1990, 11(1), p 61-66
1996Bou: A. Boudéne, K. Hack, A. Mohammad, D. Neuschütz, E. Zimmermann, G. Effenberg, S. Fries, H.L. Lukas, R.A. Konetzki, R. Schmid-Fetzer, W. Huang, B. Sundman, C. Bernard, C. Colinet, A. Pasturel, A. Pisch, F. Weiss, A. Rais, M. Ganteaume, J.C. Mathieu, J. Rogez, B.B. Argent, A.T. Dinsdale, and A. Watson, Thermochemical Measurements and Assessment of the Phase Diagrams in the System Y-Ba-Cu-O, High Temp. Mater. Sci., 1996, 35, p 159-179

1996Gro: J. Grobner. U. Kolitsch, H.J. Seifert, S.G. Fries, H.L. Lukas, and F. Aldinger, Re-Assessment of the Y-O Binary System, Z. Metallkd., 1996, 87(2), p 88-91

1996Lys: V.A. Lysenko, Thermodynamic Calculation of the Yttrium-Oxygen Phase Diagram, Neorg. Mater, 1996, p 441445, in Russian; TR: Inorg. Mater, 1996, 32(4), p 392-396

1998Oka: H. Okamoto, O-Y (Oxygen-Yttrium), J. Phase Equilib., 1998, 19(4), p 402

2007Dju: D. Djurovic, M. Zinkevich, and F. Aldinger, Thermodynamic Modeling of the Yttrium-Oxygen System, Calphad, 2007, 31, p 560-566

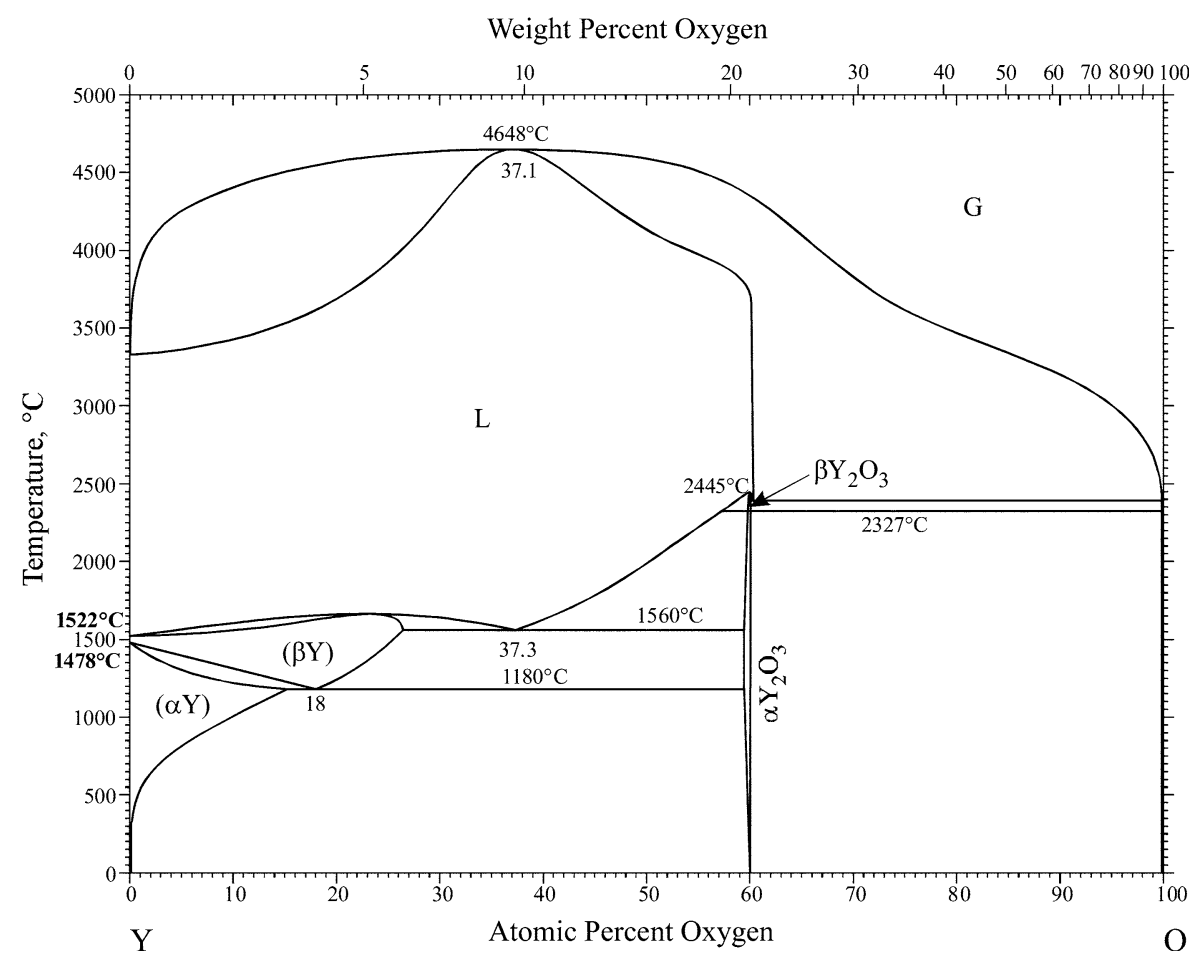

Fig. 1 Y-O phase diagram 